\title{
Algunas notas sobre la población extranjera residente en España
}

Maria Pilar Borderias Uribeondo y Maria Victoria azcárate luxan *.

INTRODUCCIÓN

El incremento de la población extranjera en nuestro pais ha sido objeto de creciente atención a partir de los años 80 , considerándose que España en la década de los años 90 puede consolidarse como un país de inmigración. El crecimiento experimentado por la población inmigrante regular en esta década ha sido superior al $100 \%$, pasando de las 181.544 personas registradas en 1980 a las 399.377 en 1990; si a éstos sumáramos los inmigrantes ilegales la cifra se elevaria notablemente. Si bien su margen es dificilmente evaluable, el Ministerio de Trabajo ha estimado en unas 170.000 las personas que se encuentran actualmente en situación ilegal en nuestro país.

Entre la población inmigrante, un caso especial lo constituye el colectivo de refugiados políticos, habiéndose reconocido dicha condición a 4.592 personas en el período comprendido entre la entrada en vigor de la Ley de Asilo y Refugio en 1984 y mediados de octubre de 1990. Actualmente, este grupo está comenzando a constituir un importante problema, debido al elevado número de personas que se declaran como refugiados para conseguir la entrada en nuestro pais, entrada que no conseguirian bajo la consideración de inmigrantes económicos. No hay más que ver que de 3.989 solicitudes efectuadas en 1989 , se ha pasado a 9.190 en los diez primeros meses de 1990.

* Departamento de Geografia. UNED. 
Esta nueva tendencia en la direccionalidad de los flujos migratorios hacia nuestro país se ha visto favorecida, por un lado, como consecuencia de la nueva situación de España en el marco de la CEE, que culminará en 1992, hecho que ha potenciado la atracción de población intracomunitaria. Por otro lado, es el propio marco internacional el que provoca la movilización de un elevado número de población del Tercer Mundo hacia los paises más desarrollados y, por tanto, la llegada a nuestro país de inmigrantes extracomunitarios, en relación con nuestra situación fronteriza de acceso a Europa.

La inmigración plantea en nuestro pais una gran polémica a todos los niveles: social, laboral y político.

Políticamente, la Ley Española de Extranjería de 1 de julio de 1985 articulaba un sistema jurídico homologable al del resto de los paises de la CEE en cuanto a normativas de entrada y permanencia de extranjeros, a la protección del mercado nacional de trabajo, y a la garantía de un asentamiento digno a los extranjeros para favorecer su integración. No obstante, a esta Ley le ha fallado la infraestructura necesaria para llevarla a cabo y gestionar de forma eficaz los flujos de inmigración, como apuntaba la OCDE al decir que el problema español en cuestión de inmigración se encuentra "en los medios limitados desplegados en un pais poco familiarizado con la gestión administrativa de la inmigración", hecho que no debe extrañar si consideramos que tradicionalmente España se ha caracterizado por el predominio de unos flujos emigratorios. En este sentido en la década de los noventa, con el proceso de unificación política de la CEE y el concepto de una Europa sin fronteras interiores, nuestro pais se constituirá en frontera de la CEE ante los paises del Tercer Mundo, lo que llevará a nuevas modificaciones en la regulación de entrada de extranjeros, como la tomada recientemente con la población magrebi (15 de mayo de 1991).

Socialmente, la población española presenta uno de los índices más altos de rechazo hacia la población extranjera entre los paises de la CEE, más acostumbrados a convivir con un heterogéneo grupo de población inmigrante. Muy significativa en este sentido resulta una encuesta, sobre racismo, efectuada por Eurobarómetro en noviembre de 1989; según ésta, los españoles presentaban unas tendencias racistas superiores a la media europea en todas las cuestiones formuladas.

Laboralmente es evidente que el elevado índice de paro en nuestro país es motivo de preocupación ante la llegada de una mano de obra extranjera, aunque, de momento, no parece resultar demasiado alarmante si tenemos en cuenta dos factores: por un lado, el elevado número de 
inmigrantes no activos procedentes de los países desarrollados tras su jubilación, que a su vez favorecen el desarrollo o, por lo menos, el mantenimiento de un sector terciario; y por otro, la entrada de un elevado porcentaje de mano de obra sin cualificar que tiende a ocupar trabajos no deseados por la población autóctona.

\section{LA INMIGRACIÓN EN EL MARCO DE LA CEE}

Si bien el crecimiento del flujo inmigratorio en España ha sido muy rápido y notable en números absolutos (cuadro I), actualmente, la proporción de extranjeros en España es aún modesta en comparación con los demás paises comunitarios.

Durante las últimas décadas, los movimientos de población y la política inmigratoria han seguido distintos caminos en los paises europeos

CUADRO I.

RESIDENTES EXTRANJEROS EN LOS PAÍSES DE LA CEE. (1987)

\begin{tabular}{|c|c|c|c|c|}
\hline & $\begin{array}{c}\text { A } \\
\text { Población } \\
\text { total } \\
\text { (millones) }\end{array}$ & $\begin{array}{c}\text { B } \\
\text { Población } \\
\text { extranjera } \\
\text { (miles) }\end{array}$ & B. $100 / \mathrm{A}$ & $\begin{array}{c}\text { Procedencia } \\
\text { CEE } \\
(\%)\end{array}$ \\
\hline Bélgica ... & 9,8 & 853,2 & 8,6 & 63,0 \\
\hline Dinamarca .. & 5,1 & 128,2 & 2,5 & 20,7 \\
\hline España ........ & 38,7 & 334,9 & 0,8 & 57,7 \\
\hline Francia (1982) & 54,3 & $3.680,1$ & 6,7 & 42,8 \\
\hline Grecia ........... & 9,9 & 193,3 & 1,9 & 57,3 \\
\hline Irlanda $(1981) \quad \ldots \ldots \ldots \ldots$ & 3,4 & 232,3 & 6,7 & 84,5 \\
\hline Italia $(1981) \ldots \ldots \ldots \ldots$ & 56,8 & 462,5 & 0,8 & 56,0 \\
\hline Luxemburgo (1981) ... & 0,3 & 95,8 & 26,2 & 92,4 \\
\hline Países Bajos .............. & 14,6 & 568,0 & 3,8 & 28,1 \\
\hline Portugal .................. & 10,2 & 89,7 & 0,8 & 26,6 \\
\hline Reino Unido * & 56,4 & $1.736,0$ & 3,0 & 43,4 \\
\hline R.F.A. $\ldots \ldots \ldots \ldots \ldots \ldots$ & 61,1 & $4.630,2$ & 7,5 & 29,7 \\
\hline CEE $\ldots \ldots \ldots \ldots \ldots \ldots \ldots$ & 320,6 & $13.003,5$ & 4,0 & 40,8 \\
\hline
\end{tabular}

* Media 1984/86.

Fuente: EUROSTAT 1989. 
industrializados y en España, debido al tradicional poder de atracción de los primeros y a la habitual emigración de nuestro pais. En los últimos quince años, la política restrictiva a la inmigración llevada a cabo por los distintos paises de la Comunidad Europea, ha llevado a una considerable reducción de estos flujos; no obstante, la movilidad ha seguido registrándose en relación, sobre todo, con los reagrupamientos familiares y con las demandas de asilo, pasando a un segundo término las motivaciones económicas. España, en cambio, a excepción de las modificaciones impuestas por la CEE con motivo de su adhesión, apenas varió su política migratoria, viéndose sus flujos migratorios determinados por condiciones externas a ella. Así, la situación en la última década se ha invertido, pasando a ser, como ya hemos dicho, un país con tendencia a un creciente flujo inmigratorio. En un principio fue el retorno de emigrantes durante la crisis de los años 70 , y después la llegada de inmigrantes comunitarios en relación con la introducción de empresas extranjeras que atraian mano de obra propia muy especializada, a lo que se suma la creciente llegada de población comunitaria no activa y la expansión de emigrantes económicos procedentes de los paises del Tercer Mundo.

En 1987, el número de ciudadanos "extracomunitarios" residentes de forma legal en el conjunto de los paises comunitarios se situaba en torno a los ocho millones, lo que suponía el $2,4 \%$ de la población total de la CEE. De ellos, casi un $25 \%$ vivia en Alemania y un $16 \%$ en Francia, seguidos por el Reino Unido $(7,5 \%)$, Holanda $(3,1 \%)$, Bélgica $(2,4 \%)$, Italia $(1,5 \%)$, y porcentajes inferiores en España, Dinamarca, Grecia, Portugal y Luxemburgo.

Por su parte, la población “intracomunitaria» desplazada de su pais se situaba en torno a los 5 millones, es decir, que más de la tercera parte de la población inmigrante en los países de la CEE pertenecía a la propia Comunidad. Los movimientos intracomunitarios presentan algunas diferencias con relación a los extracomunitarios en cuanto al país de atracción preferente; así aunque el mayor flujo se dirige también hacia los paises más industrializados, varia el orden de preferencia: en Francia se asentaba el $29,7 \%$, en Alemania el $25,9 \%$ y en el Reino Unido el $14,2 \%$, seguidos por Bélgica $(10,1 \%)$, Italia $(4,8 \%)$, Irlanda $(3,7 \%)$, España $(3,6 \%)$, Países Bajos $(3,0 \%)$, Grecia $(2,1 \%)$ y Luxemburgo $(1,6 \%)$, alcanzando unos porcentajes muy reducidos Dinamarca y Portugal. El porcentaje de residentes extranjeros intracomunitarios dentro de cada uno de los paises de la CEE resulta superior al de los extracomunitarios en Luxemburgo, Irlanda, Bélgica, España, Grecia, e Italia, quedando en el resto de los paises a niveles inferiores. 


\section{LA POBLACIÓN INMIGRANTE EN ESPAÑA: EL PREDOMINIO DE LA CEE}

El volumen de inmigrantes extranjeros en España en 1990 ascendia a 399.377 personas, cifra muy superior a las 181.544 que registraba en 1980. El incremento de la población extranjera durante esta década, ha sido un hecho generalizado en todas las provincias españolas aunque con distinta intensidad, tan sólo tres provincias han visto reducido el número de extranjeros: Badajoz $-7,6 \%$, Pontevedra $-12,2 \%$ y Teruel $-35 \%$, en cambio, esta población extranjera ha llegado a multiplicarse por seis en algunas provincias como Cádiz y Granada. En valores absolutos resulta mucho más significativo el crecimiento en esta década de la población extranjera residente en Madrid (+35.230), Málaga (+ 27.404) y Alicante $(+29.770)$. En general, son las provincias costeras del Mediterráneo y las islas las que han incrementado el número de residentes extranjeros en mayor grado, siendo tan sólo de destacar en el interior: Orense $(+2.232)$, León $(+1.126)$ y Valladolid $(+1.035)$ en relación con los inmigrantes portugueses, y Zaragoza $(+1.638)$. En la costa cantábrica, la preferencia se centra en las provincias de Vizcaya $(+2.962)$ y Guipúzcoa (+ 1.623).

Si bien el volumen de la población extranjera, en términos absolutos, llega a ser muy relevante en las provincias de asentamiento preferente (Madrid 65.817, Barcelona 43.616, Málaga 42.857, Alicante 42.813, Baleares 27.027 , etc.), su significación alcanza actualmente una reducida repercusión en el conjunto de la población total de cada provincia: es en las islas Baleares donde su proporción es mayor, representando el $2,81 \%$ del total de la población residente, seguidas por Tenerife con el $2,56 \%$, Alicante con el 2,14\%, Las Palmas con el 1,43\% y Gerona con el $1,07 \%$. Evidentemente debemos considerar que estos valores son bajos todavía si tenemos en cuenta los porcentajes alcanzados en otros países comunitarios (fig. 1.)

La población inmigrante tiende a concentrarse en las grandes áreas metropolitanas y en las zonas turísticas del litoral. En la década de los 80, cinco provincias: Alicante, Málaga, Baleares y Canarias, más las grandes metrópolis de Madrid y Barcelona, reunían al $70,4 \%$ de la población extranjera. En la actualidad, este desequilibro no ha hecho sino reforzase, concentrándose en estas áreas el $73,8 \%$ de los extranjeros (1988). 

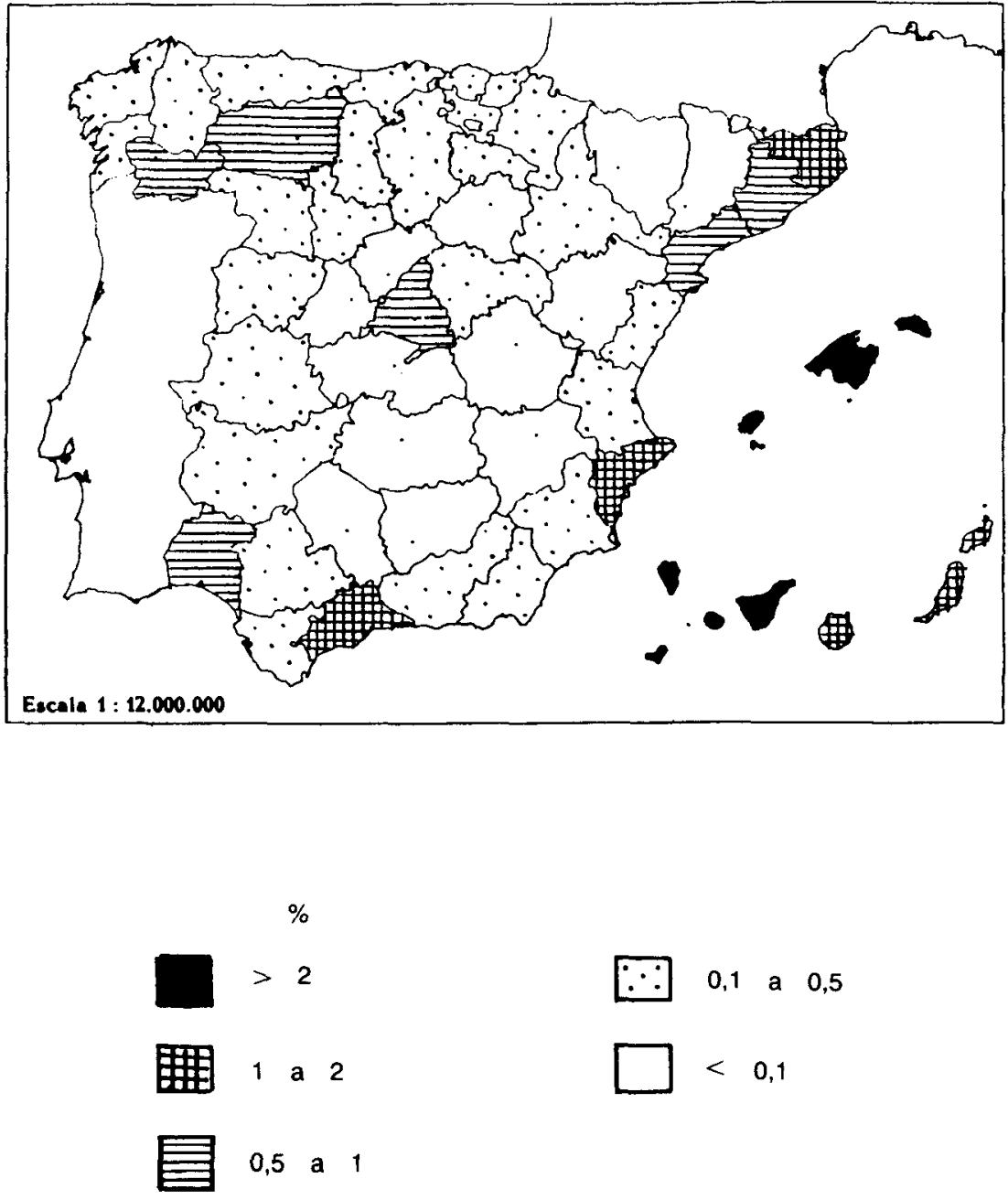

Fig. 1. Porcentaje de población extranjera en relación con la población total en cada una de las provincias. 
Algunas notas sobre la población extranjera residente en España

Una de las características más relevantes del flujo inmigratorio extranjero es el enorme predominio de inmigrantes europeos que acuden a nuestro pais, un $66 \%$, (cuadro II) y, dentro de ellos, los ciudadanos de la CEE representan en torno al $58 \%$, seguidos a mucha distancia por los procedentes de América, Asia y África (fig. 2). Este predominio de población comunitaria, sobre otros paises de procedencia, es un hecho que se produce en el $50 \%$ de los países de la CEE, como ya indicábamos anteriormente, de ahi el interés de su estudio.

La estructura de la procedencia de la población inmigrante comunitaria en España ha experimentado un notable cambio en la última década. Así, mientras que en 1980 los portugueses (22,3\%), británicos $(20,7 \%)$ y alemanes federales $(19,4 \%)$ eran las principales corrientes comunitarias y alcanzaban porcentajes bastante similares, a finales de la década el volúmen de inmigrantes del Reino Unido $(30,6 \%)$ aventajó a la RFA $(19,0 \%)$ y Portugal $(15,1 \%)$ (cuadro III). En el ámbito de los países europeos no comunitarios, Suecia y Suiza ocupan hoy en dia los primeros lugares.

Entre los demás colectivos destacan los estadounidenses, argentinos y venezolanos por el continente americano, el gran porcentaje de inmigrantes marroquies por el continente africano y la mayor afluencia de filipinos entre los residentes de Asia y Oceania.

CUADRO II.

POBLACIÓN INMIGRANTE RESIDENTE EN ESPAÑA. EVOLUCIÓN (1970-1990).

\begin{tabular}{|c|c|c|}
\hline & $\begin{array}{l}\text { TOTAL DE } \\
\text { EXTRANJEROS }\end{array}$ & $\begin{array}{l}\text { PROCEDENTES } \\
\text { OE LA CEE }\end{array}$ \\
\hline 1970 & 147.727 & 84.909 \\
\hline 1975 & 165.289 & 92.917 \\
\hline 1980 & 181.544 & 106.738 \\
\hline 1985 & 241.971 & 142.346 \\
\hline 1988 & 360.032 & 208.882 \\
\hline 1990 & 399.377 & 264.404 (Europa) \\
\hline
\end{tabular}

Fuente: IEE. Memoria anual. 

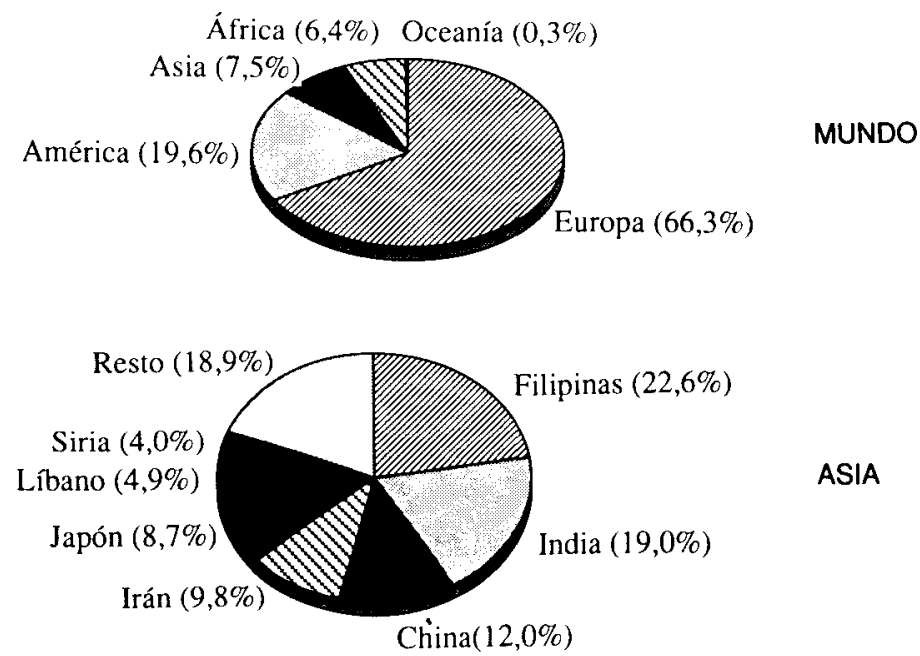

ASIA

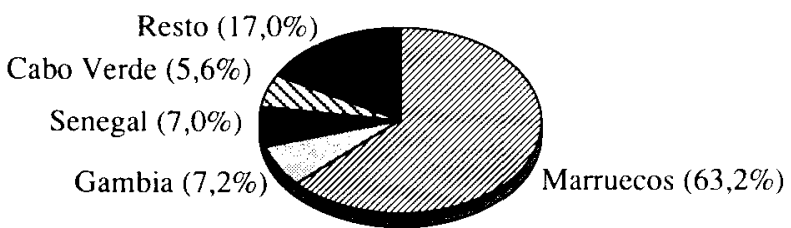

AFRICA
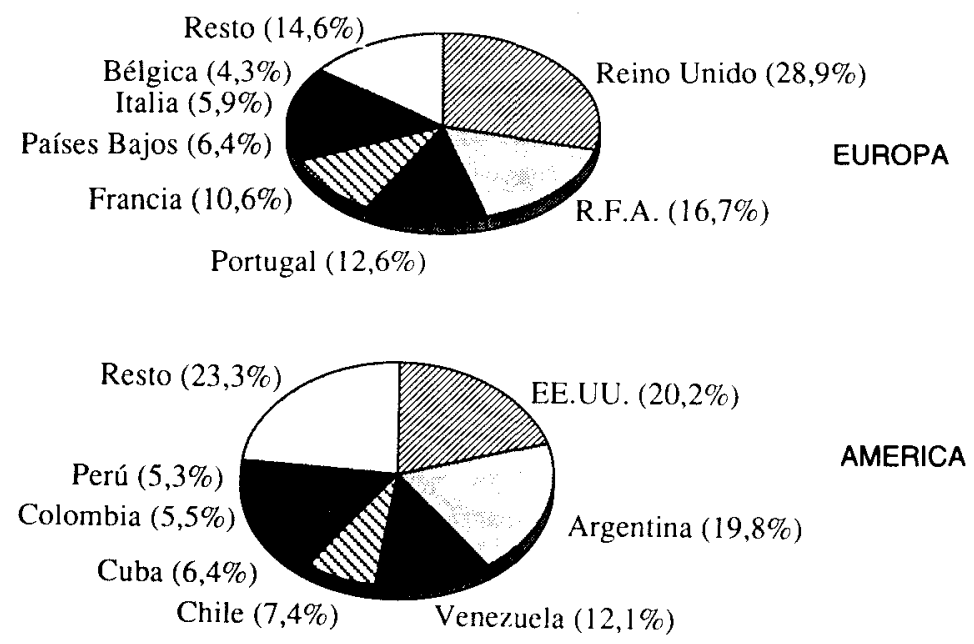

Fig. 2. Procedencia de los inmigrantes regulares en España. 
CUADRO III.

PAÍS DE PROCEDENCIA DE LOS INMIGRANTES EUROPEOS EN ESPAÑA (1990).

\begin{tabular}{|c|c|}
\hline Gran Bretaña ..... & 76.258 \\
\hline Alemania Occidental & 43.905 \\
\hline Portugal $\ldots \ldots \ldots \ldots \ldots \ldots \ldots$ & 33.532 \\
\hline Francia $\ldots \ldots \ldots \ldots \ldots \ldots \ldots$ & 27.991 \\
\hline$\ldots \ldots \ldots \ldots$ & 15.825 \\
\hline$\ldots \ldots \ldots \ldots \ldots$ & 15.825 \\
\hline$\ldots \ldots \ldots \ldots$ & 11.546 \\
\hline Otros $\ldots \ldots \ldots \ldots \ldots \ldots \ldots \ldots$ & 38.583 \\
\hline $\begin{array}{l}\text { Europa } \ldots \ldots \ldots \ldots \ldots \ldots \ldots \ldots \\
\text { Total de inmiarantes de todos }\end{array}$ & $\begin{array}{l}264.404 \text { (66 \% del total) } \\
\text { s continentes: } 399.377 \text {. }\end{array}$ \\
\hline
\end{tabular}

Fuente: Ministerio del Interior, 1990.

\section{DISTRIBUCIÓN TERRITORIAL DE LA POBLACIONN INMIGRANTE}

La población extranjera se encuentra desigualmente repartida por el territorio nacional. Son las grandes metrópolis de Madrid y Barcelona las que acogen a un mayor contingente de población extranjera $(18,2 \%$ y $12,1 \%$, respectivamente) en relación con sus posibilidades laborales, seguidas por dos importantes provincias turisticas, Málaga y Alicante $(11,9 \%$ y $11,8 \%$, respectivamente) y las islas Baleares, Tenerife y Las Palmas $(7,5 \%, 7,5 \%$ y $4,6 \%$ respectivamente), todas ellas en relación con el turismo y con un creciente sector terciario.

En general, la ubicación de la población extranjera suele ser periférica, con un marcado predominio en la costa mediterranea que contrasta vivamente con las provincias del interior, donde, a excepción de Madrid, su asentamiento resulta poco significativo, con una tendencia hacia las zonas urbanas (fig. 3). En el caso de la población comunitaria se acusa, igualmente, una tendencia a la localización periférica a lo largo de toda la costa y el mismo vacio en el interior, donde sólo Madrid presenta una fuerte capacidad de atracción.

A pesar de esta similitud en su ubicación, se observan diferencias de prioridad entre los asentamientos de la población extranjera en general y el colectivo de europeos comunitarios en particular. De los 192.983 inmigrantes comunitarios que residian en nuestro país en 1987, el mayor volúmen $(15,3 \%)$ se encuentra localizado en la provincia de Alicante, 


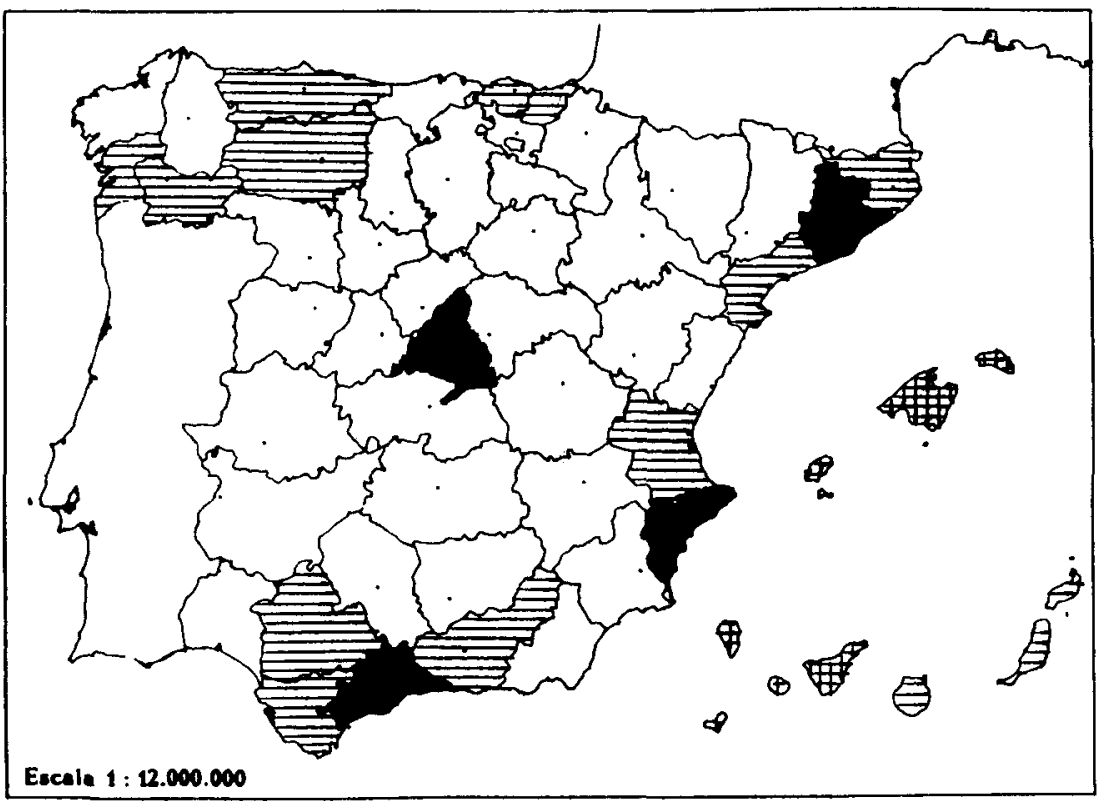

$\%$

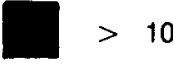

$\begin{array}{lll} & \text { a } & 5\end{array}$

果 5 a 10

$\square<1$

Fig. 3. Distribución de la población total extranjera (en \%). 
seguida de Málaga $(12,7 \%)$, las áreas metropolitanas de Madrid $(12,3 \%)$ y Barcelona $(10,5 \%)$, y las islas. El resto se encuentra repartido entre varias provincias costeras: Gerona, Tarragona, Valencia, Granada, Cádiz, Huelva, Pontevedra, Asturias, País Vasco, pero con unos valores netamente inferiores. Las provincias del interior alcanzan valores apenas representativos (fig. 4).

La distribución es diferente si comparamos el volúmen de residentes comunitarios, no con el total de los residentes de la Comunidad a nivel nacional, como hemos hecho en el caso anterior, sino con el total de la población extranjera que reside en cada una de las provincias. Son ahora las provincias limítrofes con Portugal las que muestran un mayor porcentaje de residentes comunitarios, seguidas por Alicante, Baleares y Almería, en las que los porcentajes son siempre superiores al $70 \%$. En el caso de las regiones metropolitanas de Madrid y Barcelona, los residentes comunitarios apenas alcanzan la mitad de la población residente extranjera, al tener un poder de atracción y unas características laborales más equilibradas para todos los colectivos. (fig. 5).

En líneas generales, la distribución de los residentes extranjeros procedentes de la CEE presenta ciertas diferencias según las características del área de asentamiento. Analizada la procedencia de estos extranjeros comunitarios, cabría contrastar cuatro áreas: provincias periféricas a Portugal y a Francia, áreas turísticas y áreas metropolitanas (fig. 6).

La provincias periféricas con Portugal, en claro contraste con aquellas limitrofes con Francia, presentan un neto predominio de portugueses, en relación con su proximidad al país de procedencia. Tradicionalmente, Portugal ha sido un país que ha aportado importantes contingentes de inmigrantes a España, constituyendo una significativa "cantera" de mano de obra barata para la economía sumergida, debido a las características comunes a todo este colectivo: bajo nivel cultural, pobreza, marginalidad, etc. por lo que podian encontrar trabajo en las esferas económicas más bajas de nuestra sociedad. Actualmente, todavía juega un importante papel en esta distribución su baja cualificación laboral, no tenemos más que observar cómo el $90,4 \%$ de los portugueses residentes en España que han solicitado permisos de trabajo lo han hecho para actividades que no requieren una cualificación profesional, por lo que prefieren localizarse en regiones próximas a su lugar de origen. Las provincias de León y Asturias acogen también a un importante número de portugueses en relación con las posibilidades de empleo en las minas y en el sector forestal.

El grupo de portugueses resulta también significativo en Madrid y en el conjunto de las provincias limitrofes a Francia, donde su volumen se 


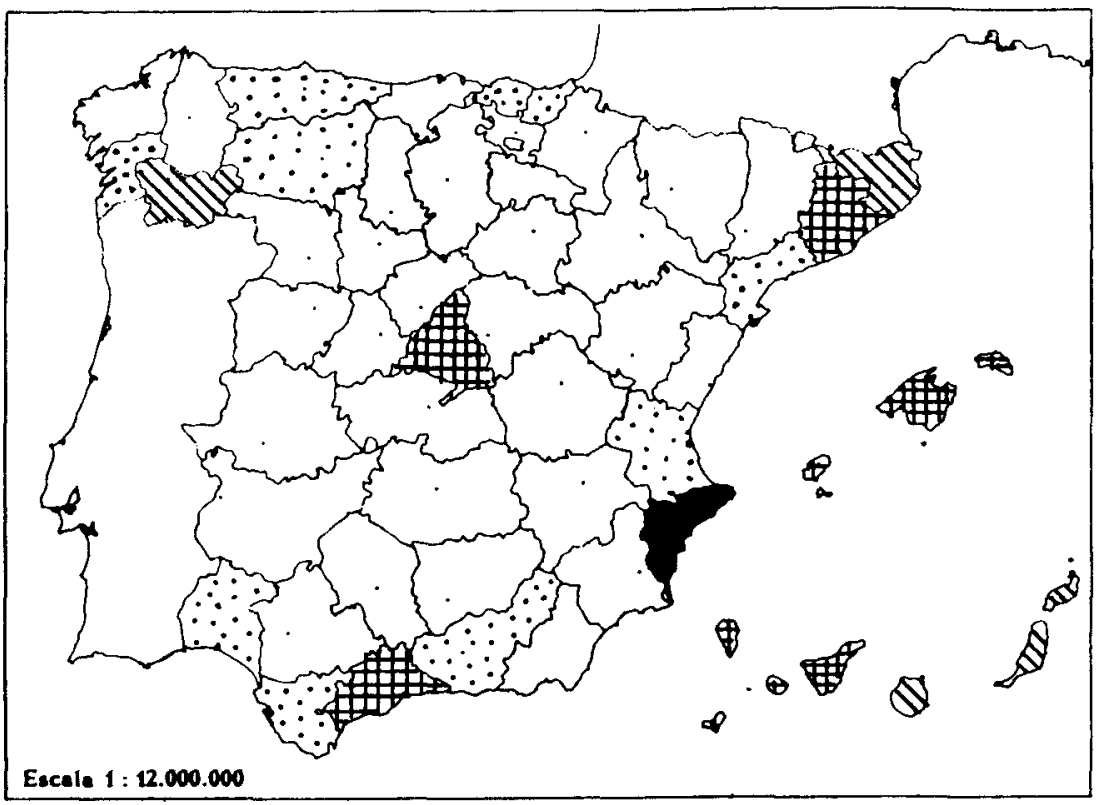

$\%$

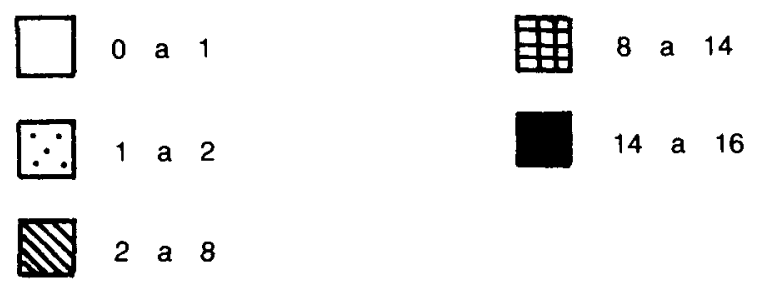

Fig. 4. Distribución de residentes extranjeros de la CEE (en \%). 
Algunas notas sobre la población extranjera residente en España
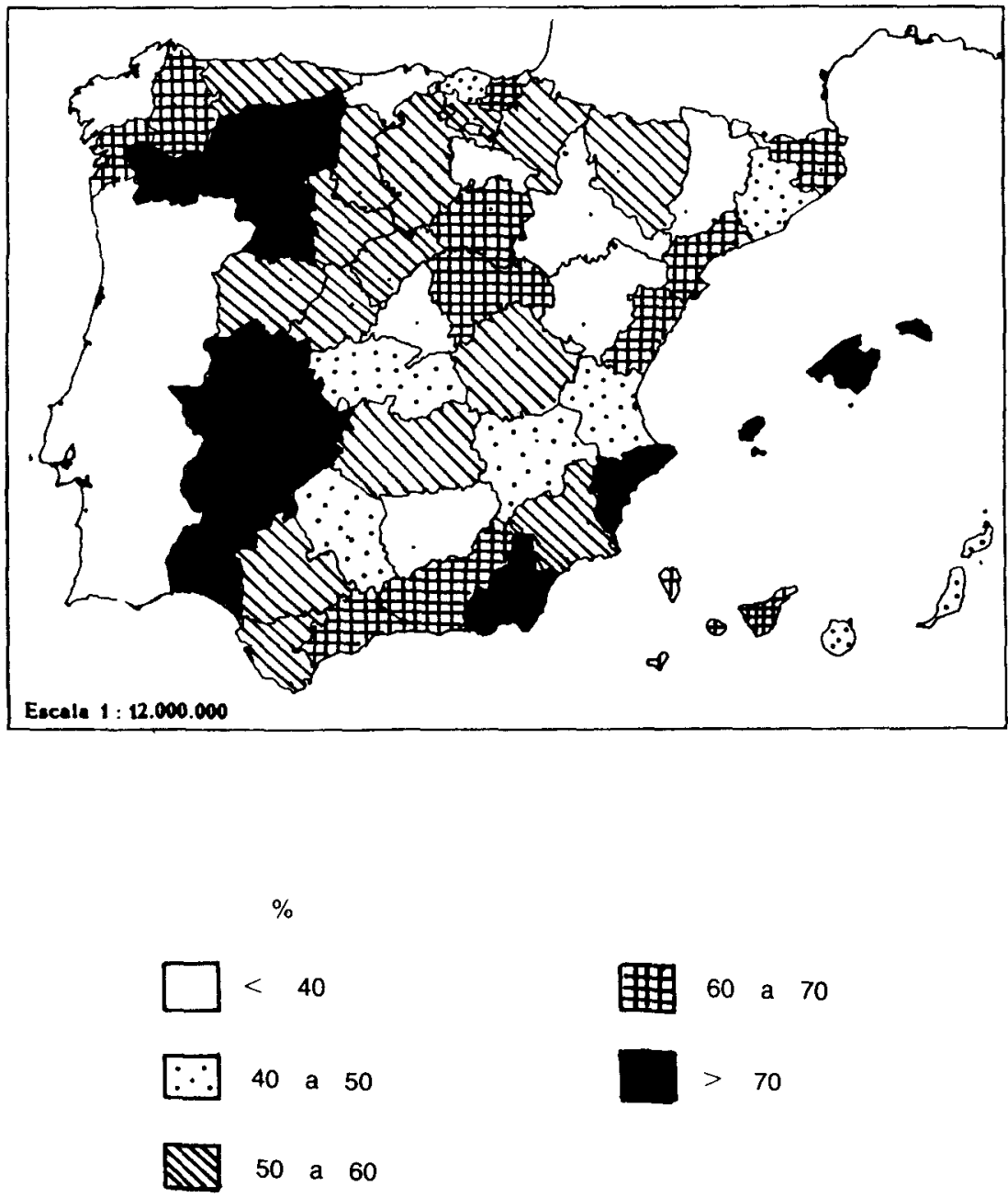

Fig. 5. Porcentaje de residentes extranjeros comunitarios en relación con el total de población extranjera en cada provincia. 


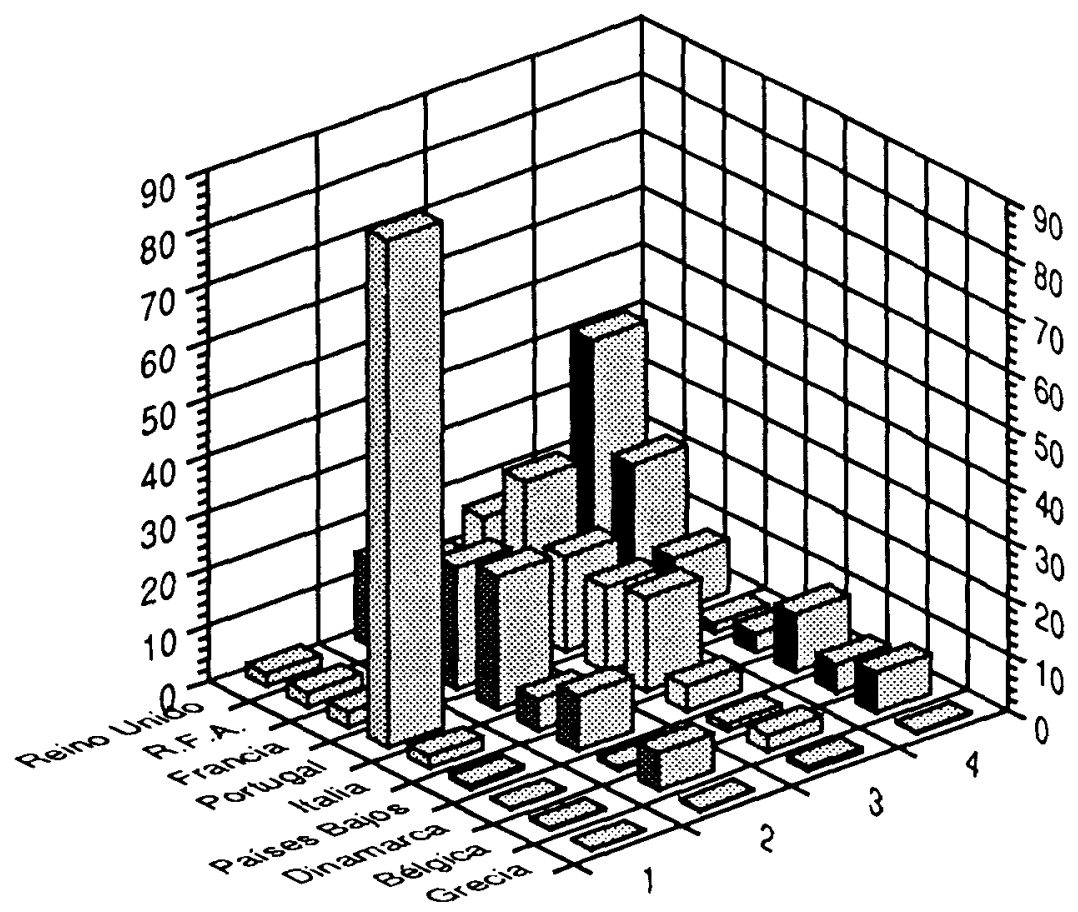
1. Provincias periféricas a Portugal.
2. Provincias periféricas a Francia.
3. Áreas metropolitanas.
4. Áreas turísticas.

Fig. 6. Procedencia contrastada de los inmigrantes comunitarios en las principales áreas de asentamiento. 
equipara a otros colectivos europeos, ocupándose, igualmente, en servicios y en puestos de baja cualificación profesional.

En contraste con este hecho, hay que destacar que no ocurre 10 mismo con el caso de las provincias periféricas con Francia, donde las características inmigratorias son muy diferentes a las que acabamos de observar en Portugal, es decir, no se observa un marcado predominio de población del pais próximo, sino que los inmigrantes tienen una mayor diversidad de procedencia. Al tratarse de regiones más industrializadas requieren una mano de obra más especializada, lo que da lugar a una mayor competencia laboral y por tanto a una mayor diversidad de los paises de procedencia de la población inmigrante alli asentada. Asi, exíste un neto predominio de inmigrantes procedentes de los paises industrializados (Francia, R.F.A. y R.U.), en proporciones muy equilibradas. Este hecho se relaciona directamente con el porcentaje de permisos laborales para actividades muy cualificadas, en las que los colectivos de franceses, alemanes y británicos, alcanzan el $53,7 \%$, al $46,5 \%$ y al $43,4 \%$, respectivamente.

Las provincias turísticas presentan un destacado predominio de población procedente de los paises desarrollados, en relación con una población de edad avanzada que busca las ventajas climáticas de nuestro país. Así, los británicos suponen el mayor porcentaje de población, seguidos por alemanes, franceses, holandeses y belgas. Una cuarta parte de los ingleses se localizan preferentemente en Alicante, seguido de Málaga, Baleares y Canarias. Los alemanes tienden a concentrarse en mayor número en Baleares, Canarias y Alicante. Por su parte, los franceses se instalan preferentemente en Alicante, Málaga, Canarias y Baleares. No obstante, la población adulta activa de estos colectivos, busca también una localización preferente en las grandes áreas metropolitanas.

Las grandes áreas metropolitanas, Madrid y Barcelona, constituyen los principales núcleos de atracción de toda la población trabajadora extranjera. Entre la población comunitaria, es la RFA la que cuenta con un mayor volúmen de población en estas áreas $(26,2 \%)$, seguida de Francia $(16,4 \%)$, Italia $(16,4 \%)$, Reino Unido $(16,2 \%)$ y Portugal $(14,7 \%)$, y ya a mayor distancia quedan los Paises Bajos, Bélgica, Dinamarca y Grecia.

\section{LA INMIGRACIÓN IRREGULAR INTRACOMUNITARIA}

Las características socioeconómicas de nuestro país en contraste con el resto de los países comunitarios, no establece, inicialmente, una 
situación propicia para una generalizada entrada ilegal de inmigrantes, en el sentido que tradicionalmente se entiende como «ilegales". No obstante, si analizamos detenidamente la situación, existe un considerable número de población intracomunitaria en situación ilegal en nuestro país. Por ejemplo, IzQUiERdo Escribano, A., (1990) calculaba que en 1985 un $26 \%$ de los inmigrantes europeos comunitarios se encontraba en situación irregular en España.

Entre los extranjeros comunitarios que se encuentran en situación ilegal en nuestro país habria que diferenciar dos grupos: la residencia irregular de los inmigrantes «turísticos" procedentes de los países comunitarios más desarrollados (jubilados que sobrepasan los seis meses de estancia en nuestro pais), y los inmigrantes "económicos" ilegales procedentes de los paises comunitarios menos desarrollados.

Los jubilados que residen más de seis meses en nuestro país representan un elevado porcentaje de la población ilegal comunitaria, puesto que nuestra legislación establece que los turistas que superen los seis meses de estancia necesitan un permiso de residencia. Este es un caso en el que no cabria pensar en un ocultamiento de residencia sino en una simple despreocupación por no tener un interés propio para ellos este requisito, o por desconocimiento de las legalidades que requieren los plazos que ellos consideran como un simple hecho de turismo.

El segundo grupo, los inmigrantes propiamente ilegales, también representa un elevado porcentaje dentro de la población comunitaria y está en gran parte configurado por el colectivo de portugueses, muchos de los cuales son de raza gitana.

La afluencia portuguesa hacia nuestro pais data de los años 60 , de modo que puede considerarse como uno de los colectivos de inmigrantes económicos más tradicionales. El volumen de portugueses en situación ilegal es elevado, ocupa el tercer lugar entre la población ilegal tras los marroquies y el conjunto de africanos, considerándose que entre un $10 \%$ y un $20 \%$ se encuentra en situación ilegal. Esta población ilegal entra clandestinamente en España, y, en líneas generales, procede de las esferas más pobres de Portugal, cuenta con un bajo nivel de instrucción y una baja o nula cualificación laboral, por lo que se dedica a trabajos temporales en actividades muy diversas (minería, jornaleros del campo, peones industriales, construcción, servicio doméstico, venta ambulante, actividades marginales y economia sumergida), que alternan, en muchos casos, con la mendicidad. Su bajo nivel socioeconómico les obliga a instalarse en la periferia cultural, urbana y económica de nuestra sociedad, ocupando con frecuencia chabolas e infraviviendas. 
La situación de irregularidad de estos colectivos va a tener poca duración, hasta 1993, fecha en que España y Portugal se incorporarán plenamente a la CEE y serán eliminadas las fronteras interiores.

\section{CONCLUSIONES}

Durante esta última década, España, que durante muchos años ha sido un país de emigración, se está convirtiéndo en lugar de destino de una creciente inmigración, ya sea legal o ilegal.

Dos son las características más relevantes de este flujo inmigratorio, por una parte, el enorme predominio de inmigrantes europeos, en su mayoría procedente del resto de los paises miembros de la Comunidad, y por otra, su localización preferente en las grandes áreas metropolitanas y regiones turísticas del litoral mediterráneo e islas.

La presión creciente de los paises del Maghreb hacia la Europa meridional y los acontecimientos políticos de la Europa del Este, cuyas repercusiones migratorias son ya notables en muchos paises miembros, no han hecho sino modificar aún más el marco de referencia.

En definitiva, aunque porcentualmente la presencia extranjera en España sea aún muy inferior a la existente en otros paises europeos, el incremento de los flujos migratorios hacia nuestro pais, favorecidos por la realidad demográfica y económica internacional, es un hecho innegable que nos obliga a poner en marcha una política de extranjería coherente y global que preserve nuestros intereses y tenga en cuenta las obligaciones impuestas por nuestra pertenencia a la CEE, donde la desaparición de los controles fronterizos entre los Estados miembros será uno de los simbolos de la Europa de 1993. 


\section{FUENTES Y BIBLIOGRAFIA}

COMISIÓN DE LAS COMUnIDADES EuRopeas. 1990: «Políticas de inmigración e integración social de los inmigrantes en la CEE». Bruselas. Comisión de las Comunidades Europeas.

Comunicado del Gobierno al Congreso de los Diputados. 1990: «Situación de los extranjeros en España. Líneas básicas de la politica española de extranjería". Madrid.

EUROSTAT. 1989: “Estadísticas demográficas». Bruselas.

I.E.E «Memoria anual». AÑOS 1985, 1986, 1987 y 1988. Madrid. Ministerio de Trabajo y Seguridad Social. Dirección General del I.E.E.

INSTITUTO ISOPLAN. 1989: Estudio sobre el análisis estadístico de los movimientos migratorios en España, dentro del programa «Effets sociaux et économiques de l'inmigration en provenance de Pays Tiers dans les Pays Méridionaux de la CEE». Saarbrücken/Bonn-RFA. Comisión de la CEE.

IZQUIERDO ESCRIBANO. A. 1990: "La inmigración en España». Informe realizado para el I.E.E. Madrid, I.E.E. 